\title{
Idiopathic sclerosing mesenteritis in paediatrics: Report of a successfully treated case and a review of literature
}

\author{
Vijay Viswanathan, Kevin J Murray
}

\begin{abstract}
A 6 year old female with symptoms of small bowel obstruction underwent an exploratory laparotomy which revealed widespread evidence of inflammatory fibrotic adhesions involving the jejunal mesentery. In view of persistent growth failure, chronic anaemia, elevated acute phase reactants and imaging evidence of a diffuse progressive inflammatory process, the child was treated with corticosteroids and methotrexate with complete response. The literature on juvenile idiopathic sclerosing mesenteritis has been reviewed.
\end{abstract}

\section{Background}

Idiopathic sclerosing mesenteritis (ISM) is an uncommon disease involving the small bowel mesentery and characterised by chronic inflammatory changes ultimately progressing to fibrosis. The first reported series featured 34 cases of "retractile mesenteritis and mesenteric sclerosis"; published in 1924 [1-3]. It has been described variously as fibrosing mesenteritis, retractile mesenteritis, liposclerotic mesenteritis, xanthogranulomatous mesenteritis, mesenteric Weber Christian disease and systemic nodular panniculitis [4]. These names possibly reflect the underlying pathology involved with mesenteric lipodystrophy (predominant fatty degeneration), mesenteric panniculitis (chronic inflammation) and retractile mesenteritis (predominant fibrosis) being the common histologic variants. It has been postulated that these variants represent the varied spectrum of a single disease process which could be termed idiopathic sclerosing mesenteritis [5].

Though the exact aetiology remains obscure, proposed mechanisms include prior abdominal trauma/surgery, autoimmunity, infection and ischemia [6]. A wide range of therapeutic initiatives have been reported including corticosteroids, colchicine, immunosuppressives (cyclophosphamide and azathioprine), tamoxifen, thalidomide and hormonal therapies with varying success [6,7]. The

\footnotetext{
* Correspondence: kevin.murray@health.wa.gov.au

* Correspondence: kevin.murray@health.wa.gov.au
Department of Pediatric Rheumatology, Princess Margaret Hospital for Children, Perth, WA, Australia
}

disease is considered rare in the pediatric age group with only 16 cases reported to date. We describe a case of ISM in a young girl who was treated successfully with corticosteroids and methotrexate, and briefly review the pediatric literature on this subject.

\section{Case presentation}

A 6 year old girl presented at a local hospital with an acute onset of abdominal pain, nausea and bilious vomiting. A history of constipation, recurrent vomiting associated with high fever in the preceding 12 months was elicited. Clinical examination was reported to be normal at the time. Complete blood counts revealed haemoglobin $(\mathrm{Hb}) 94 \mathrm{~g} / \mathrm{l}, \mathrm{WBC} 18.4 \times 0^{9} / \mathrm{l}$ (Absolute PMN $15.6 \times 10^{9} / \mathrm{l}$, Lymph $\left.2.0 \times 10^{9} / \mathrm{l}\right)$ and platelets 663 $\times 10^{9} / \mathrm{l}$. Her ESR was elevated at $54 \mathrm{~mm} / \mathrm{hr}[1-15 \mathrm{~mm} /$ $\mathrm{hr}$ ) and CRP $84 \mathrm{mg} / \mathrm{l}(<10 \mathrm{mg} / \mathrm{l})$. Ultrasonography of the abdomen revealed diffuse, mesenteric lymphadenopathy. A barium meal with follow through suggested a small bowel obstruction. A laparotomy showed extensive intraperitoneal adhesions, mesenteric lymphadenopathy and a tight jejunal band with obstruction. The adhesions were divided, the obstruction was relieved and the patient's bowel function recovered steadily. Tissue cultures were negative. Histopathological analysis of the peritoneal tissue revealed fibro-fatty tissue with extensive fibrosis throughout, infiltrated by many scattered lymphocytes, plasma cells and occasional neutrophils but no malignant cells. The single lymph node examined revealed dilated sub-capsular sinuses with an expanded 
para-cortex with mixed histiocytes and occasional immunoblast with no granulomas, Reed Sternberg cells or any evidence of lymphoma. Ziehl-Neelsen stains were negative for tuberculosis organisms as was subsequent culture. The clinical condition improved slowly over the subsequent 2 weeks and she was discharged on oral iron supplements. No evidence of mono-clonality was seen on flow cytometry for immuno-phenotyping of lymph node tissue.

Three months later, she moved interstate and presented to the gastroenterology clinic at our hospital with continued weight loss and an exacerbation of abdominal pain and vomiting of fecal matter. Upper and lower endoscopies were normal. MRI of the abdomen revealed apparent thickening of a loop of proximal jejunum in the left mid abdomen with enlarged mesenteric lymph nodes. CT scan revealed evidence of a subtle attenuation in the mesentery with diffuse lymphadenopathy (Figure 1A). The symptoms of obstruction settled with conservative management. At one month follow up, her haemoglobin remained depressed, $87 \mathrm{~g} / \mathrm{l}$, WBC $15.0 \times 10^{9} / \mathrm{l}$ with thrombocytosis. She had lost $7 \mathrm{kgs}$ in weight (from the first presentation), had recurrent abdominal pain and required a second admission for a partial obstruction which resolved with conservative management.

A rheumatology consultation was made. Review of the case revealed multiple episodes of subacute small bowel obstruction with chronic anaemia, weight loss, and a chronic inflammatory process with fibrosis on mesenteric biopsy and elevated acute phase reactants. Further investigations revealed a borderline positive ANA of 1:40 (speckled pattern), a negative dSDNA and rheumatoid factor (RF). Total serum proteins were $82 \mathrm{~g} / \mathrm{l}$, albumin $40 \mathrm{~g} / \mathrm{l}(32-48 \mathrm{~g} / \mathrm{l})$, globulins $42 \mathrm{~g} / \mathrm{l}(23-35 \mathrm{~g} / \mathrm{l})$, and serum IgG $15.7 \mathrm{~g} / \mathrm{l}(6-12.3 \mathrm{~g} / \mathrm{L})$ indicating mild hypergammaglobulinemia. IgG subclasses IgG1 11.1(4.0$10.8 \mathrm{~g} / \mathrm{L})$, IgG2 4.3 (0.8-4.1 g/L), IgG 30.4 (0.1-1.4 g/L), IgG4 $1.47(<1.9 \mathrm{~g} / \mathrm{L})$ were unremarkable. An abdominal angiogram was done to screen for major vessel vasculitis such as polyarteritis nodosa, and was negative.

A diagnosis of idiopathic sclerosing mesenteritis was made and the child was treated with 3 daily pulses of methyl prednisolone therapy repeated monthly for 3 months. She made a remarkable and rapid clinical recovery with marked reduction in fatigue, abdominal pain and resolution of fever within 2 weeks. Four weeks into treatment, laboratory investigations revealed significant improvement; $\mathrm{Hb} 118 \mathrm{~g} / \mathrm{l}$, WBC $10.1 \times 10^{9} / 1$ platelets $490 \times 10^{9} / 1$ and ESR $3 \mathrm{~mm} / \mathrm{hr}$. Subcutaneous methotrexate $\left(10 \mathrm{mg} / \mathrm{m}^{2}\right)$, total dose $10 \mathrm{mg}$ once a week was started for long term immunomodulation and steroid sparing effects. At 6 months follow - up from the onset of treatment, she had gained $3 \mathrm{kgs}$, was completely asymptomatic and her laboratory investigations remained normal. Her repeat $\mathrm{CT}$ scan this time had revealed resolution of the lymphadenopathy with normal mesentery (Figure 1b). Currently at 18 months follow up, she is under regular 3 monthly follow-up, off steroids and only on subcutaneous methotrexate at $(10 \mathrm{mg} /$ $\mathrm{m}^{2)}$ now $12.5 \mathrm{mg}$. Figure 2 illustrates the impressive and sustained response to treatment evidenced by her haemoglobin and ESR results over time.

\section{Discussion}

First reported in 1924 as 'retractile sclerosing mesenteritis', ISM was reprised in a case series which reported it to be a benign disease in general. ISM is considered a rare disorder of late adult life with relatively few cases reported in world literature [1-3]. Only 3 major case series have been reported in adults comprising 53,84

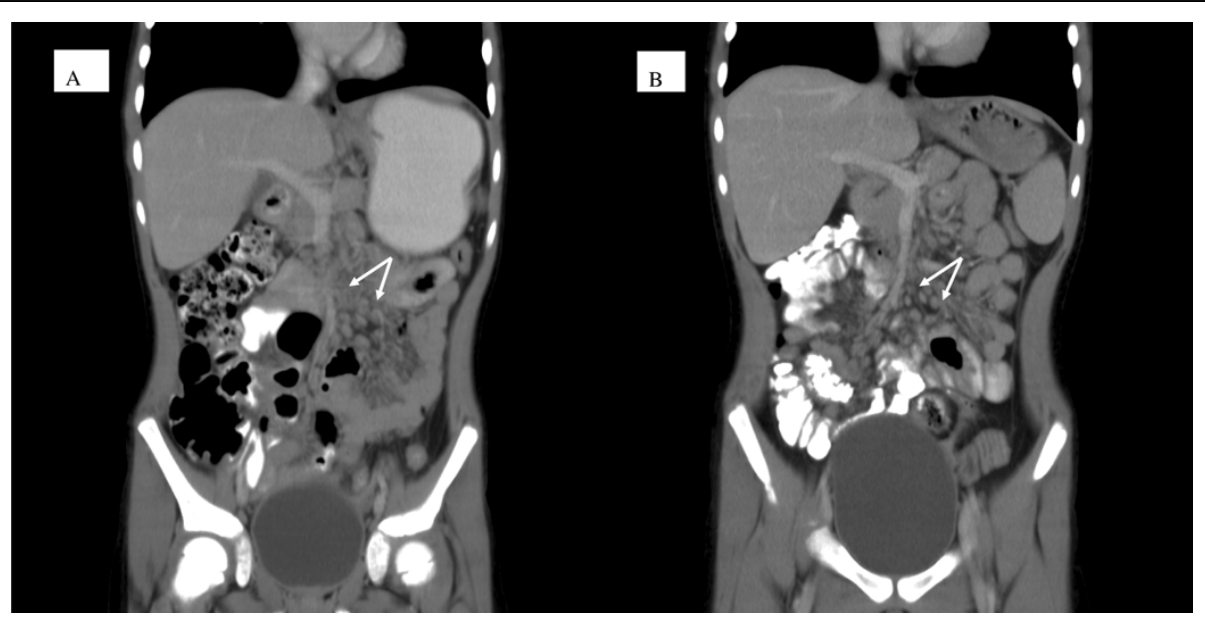

Figure $1 \mathrm{~A}$ (Pre treatment) Radiological findings demonstrating altered attenuation of mesentery and diffuse lymphadenopathy (white arrows). B (Post treatment) Resolution of lymphadenopathy. 


\section{Haemoglobin response to treatment}

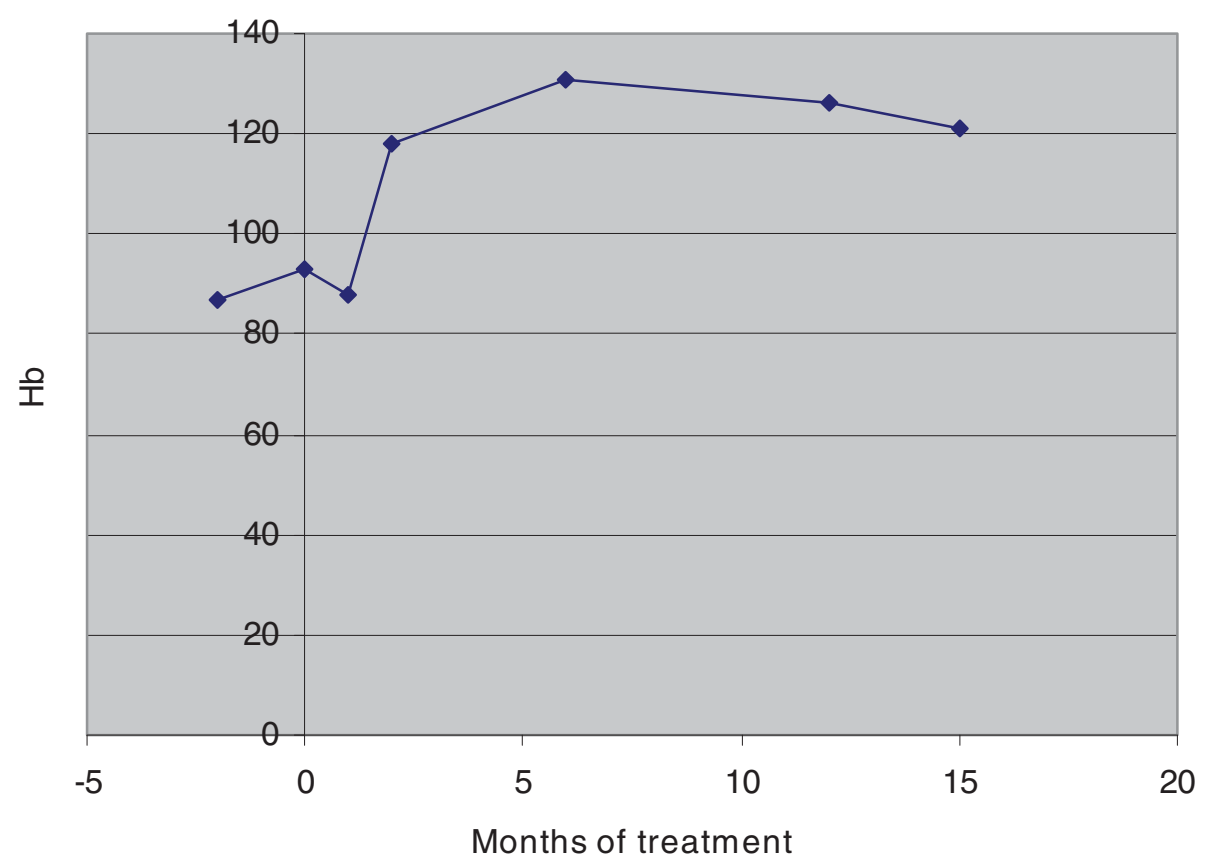

ESR response to treatment

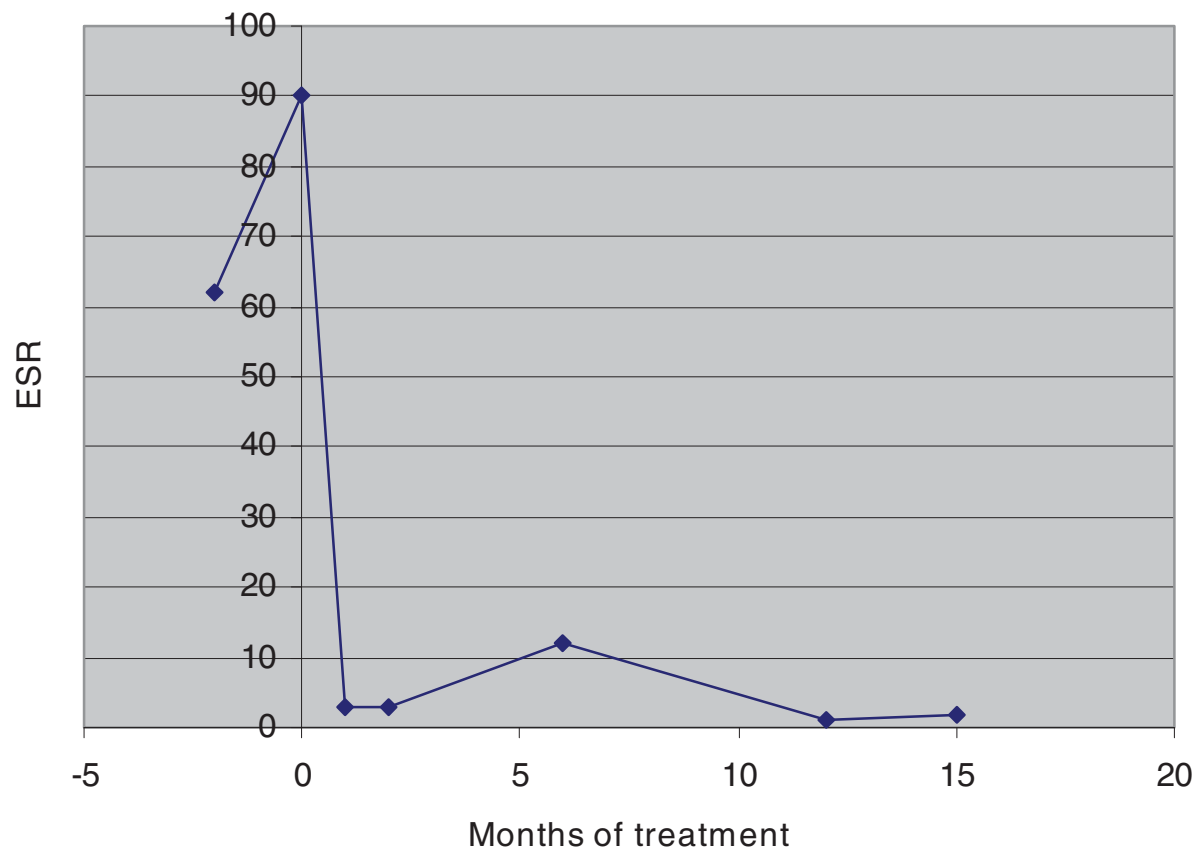

Figure 2 Response to treatment of patients ESR and Haemoglobin in month since the start of treatment. 
and 92 patients [5,6,8]. To our knowledge, only 17 pediatric cases including our own have been reported (see Table 1), with no gender predominance and age at diagnosis averaging 6.5 years (range 18 months -12 years).

Various patho-physiological mechanisms suggested include previous surgery, trauma, hypoxia, allergy, infection and autoimmunity $[6,9,10]$. Concurrent intra abdominal pathologies have been reported in adults including lymphoma and ovarian tumours. One child had a coincidental presence of a Meckels diverticulum [11] while another had a blunt trauma to the abdomen a week before developing clinical manifestations. (See table 1). Other associated immuno-hematological anomalies such as common variable immunodeficiency, polyclonal gammopathies, acute myeloid leukaemia and myelodysplasias have been reported in adults.
Understandably monoclonal/oligoclonal B cell expansion has been suggested as a possible mechanism, as it has in a possibly related disorder, retroperitoneal fibrosis. Inflammation in ISM has been attributed to adipocytokines, including adiponectin, resistin, leptin, IL-6, and TNF- $\alpha$. Macrophages found in adipose tissue may transdifferentiate from local preadipocytes, supporting the hypothesis that adipocytes and macrophages may be interconvertible, implicating mesenteric adipose tissue in disorders such as ISM [12]. Autoimmunity has been associated with ISM, including the co-occurrence of Sjogren syndrome, sarcoidosis, rheumatoid arthritis and ankylosing spondylitis. Similarly an association of ISM and other sclero-fibrosing disorders in other organs has been reported in adults [13,14]. (More recently, ISM has been regarded as a possible subset of IgG4 related sclerosing disorders with increased expression in the lesional

Table 1 Clinical manifestations and course of illness in 17 children with sclerosing mesenteritis

\begin{tabular}{|c|c|c|c|c|c|c|}
\hline $\begin{array}{l}\text { Pt. } \\
\text { no }\end{array}$ & Author/year & $\begin{array}{l}\text { Age/ } \\
\text { Sex }\end{array}$ & $\begin{array}{l}\text { Presenting features/ } \\
\text { duration }\end{array}$ & Treatment & Outcome & $\begin{array}{l}\text { Special features (if } \\
\text { any) }\end{array}$ \\
\hline 1 & $\begin{array}{l}\text { McGee et.al } \\
\text { [18](1965) }\end{array}$ & $6 / M$ & $\begin{array}{l}\text { A, Asc/unknown } \\
\text { duration }\end{array}$ & $5 x$ & $\begin{array}{l}\text { Died }, 3 \text { weeks post surgery } \\
\text { (Bacterial endocarditis ) }\end{array}$ & $\begin{array}{l}\text { No 'persistent fibrosis } \\
\text { on autopsy.' }\end{array}$ \\
\hline 2 & $\begin{array}{l}\text { Soergel[16]et. } \\
\text { al (1966) }\end{array}$ & $14 / \mathrm{M}$ & $\begin{array}{l}\mathrm{A}, \mathrm{WL}, \mathrm{F} / \text { Recurrent } \\
\text { symptoms over } 12 \text { yrs }\end{array}$ & Sx & $\begin{array}{l}\text { Died ,12 yrs after initial } \\
\text { symptom }\end{array}$ & $\begin{array}{l}\text { Steatorrhea, secondary } \\
\text { amyloidosis }\end{array}$ \\
\hline 3 & $\begin{array}{l}\text { Black et.al } \\
{[19](1968)}\end{array}$ & $8 / F$ & $A, N, V, D, F, M / 6$ weeks & $\begin{array}{l}\text { Sx, Partial resection and } \\
\text { ileocolostomy }\end{array}$ & UR/NF , $5 \mathrm{mths}$ & $\begin{array}{l}\text { Blunt trauma one week } \\
\text { prior. }\end{array}$ \\
\hline 4 & $\begin{array}{l}\text { Spark et.al[17] } \\
\text { (1971) }\end{array}$ & $6 / \mathrm{M}$ & A/M Two weeks & $\begin{array}{l}\text { Sx/Hemi colectomy with ileo colic } \\
\text { anastomosis }\end{array}$ & UR/NF ,9 mths & -—————- \\
\hline 5 & $\begin{array}{l}\text { Misaka et.al } \\
{[20](1977)}\end{array}$ & $4 / F$ & $\mathrm{~A} / \mathrm{C} / \mathrm{N} / \mathrm{AsC}$ & Sx/enterostomy with resection & UR/NF , 12 mths & -——-—-—— \\
\hline 6 & $\begin{array}{l}\text { Melo et.al } \\
{[21](1980)}\end{array}$ & $13 / F$ & $A, N, V, M$ & Sx/hemicolectomy & NR & -——————— \\
\hline 7 & $\begin{array}{l}\text { Dor et.al } \\
\text { (1982) }\end{array}$ & $10 / \mathrm{F}$ & $\mathrm{F}$ & $\begin{array}{l}\text { Sx/enterectomy, partial splenectomy } \\
\text { and partial pancreatectomy }\end{array}$ & NR & SLE \\
\hline 8 & $\begin{array}{l}\text { Cakmak }{ }^{22} \text { et. } \\
\text { al (1986) }\end{array}$ & $4 / M$ & $\mathrm{~A} / \mathrm{C} / \mathrm{F} / \mathrm{N}$, acute onset & Sx/Transverse laparotomy & UR/NF, 20 mths. & $\begin{array}{l}\text { Recurrence after } 2 \\
\text { weeks. }\end{array}$ \\
\hline$\overline{9}$ & $\begin{array}{l}\text { Jona et.al } \\
\text { [23](1987) }\end{array}$ & $5 / F$ & A, F/7 days & Sx/Right hemicolectomy & UR/NF ,51/2 yrs & Bacterial peritonitis. \\
\hline$\overline{10}$ & $\begin{array}{l}\text { Davis et.al }{ }^{24} \\
\text { (1992) }\end{array}$ & $3 / M$ & A, An, V/one day & Sx/No resection. & UR/NF 2 mths. & Hemo Peritoneum \\
\hline$\overline{11}$ & $\begin{array}{l}\text { Ueda et.al } \\
{[25](1997)}\end{array}$ & $12 / \mathrm{F}$ & $\mathrm{V}, \mathrm{M} / 2$ days & SRAM & UR/NF ,6 months & $\begin{array}{l}\text { Fulminant hep A with } \\
\text { recurrent ascites }\end{array}$ \\
\hline 12 & $\begin{array}{l}\text { Ito [20]et.al } \\
\text { (1998) }\end{array}$ & $8 / \mathrm{M}$ & NR & SRAM & UR/NF, 9 years & \\
\hline 13 & $\begin{array}{l}\text { Hakguder et. } \\
\text { al }{ }^{11}(2000)\end{array}$ & $4 / \mathrm{M}$ & A, N, An/Not specified & SRAM & UR/NF, 6 months. & Meckels diverticulum \\
\hline$\overline{14}$ & $\begin{array}{l}\text { Kawano [20] } \\
\text { et.al (2003) }\end{array}$ & $2 / \mathrm{M}$ & F/1 month & SRAM & UR/NF & -—————- \\
\hline 15 & $\begin{array}{l}\text { Kawano [20] } \\
\text { et.al (2003) }\end{array}$ & $4 / M$ & F, M/Not specified, & SRAM & UR/NF & -—-- \\
\hline 16 & $\begin{array}{l}\text { Kawano [20] } \\
\text { et.al (2003) }\end{array}$ & $6 / F$ & F, M/Not specified & SRAM & UR/NF & -—-—-—- \\
\hline 17 & $\begin{array}{l}\text { Our case } \\
\text { (2008) }\end{array}$ & $6 / F$ & $\begin{array}{l}\text { A, V, WL, C/Recurrent } \\
\text { episodes } 6 \text { months }\end{array}$ & Sx, Steroids, Methotrexate & UR/NF, 6 months. & $\begin{array}{l}\text { Methotrexate first } \\
\text { reported pediatric case. }\end{array}$ \\
\hline
\end{tabular}

Pt; Patient, A; Abdominal pain, An; Anorexia, Asc; Ascites, W; Weight loss, F; Fevers, M; Mass N/V; Nausea/Vomiting, C; Constipation, D; Diarrhoeas, Mtx; Methotrexate, St; Steroids, Sx; Surgery, SRAM; Surgical resection and anastomosis, UR; Uneventful recovery, NF; Normal follow up, NR; Not reported. 
plasma cells. No evidence of elevated IgG4 was found in this case but the biopsy was not specifically stained for subclasses [15]. Apart from one child with SLE none of these has been reported in pediatric literature to date [16]. Our case did exhibit some features of autoimmunity with a positive ANA and hypergammaglobulinemia.

The onset of the disease may be acute, insidious or have recurring episodes before the actual diagnosis is made [17]. Varied clinical manifestations have been reported, primarily due to mechanical effects of the encasing mass/inflammation involving bowel loops, mesenteric vessels and lymphatics. These include abdominal pain with a clinically palpable mass, bilious vomiting, diarrhoea, constipation and abdominal distension. Associated features of chronic inflammation including prolonged pyrexia, weight loss, and progressive anaemia can be seen but may be more prominent in the early phase.

In the pediatric cases, of the 17 children, 4 were described as mesenteric panniculitis while the remaining 13 termed sclerosing mesenteritis. Eleven (64.7\%) children presented with abdominal pain, 7 (41\%) had vomiting, 4 (23.5\%) with bowel symptoms in the form of constipation or diarrhoea, 8 (47\%) with associated fever and $2(11.7 \%)$ with weight loss. Only 5 (29\%) children had a clinically palpable mass corroborated on exploration. Laboratory investigations were usually non specific ranging from normal to neutrophilic leucocytosis and variable elevation of acute phase reactants. Five of the $13(38 \%)$ children tested demonstrated anemia and 9 (62\%) leucocytosis. 4 (30\%) children had normal white cell counts. Elevated acute phase reactants ESR/CRP were only reported in 5 children [18-26].

Most cases are diagnosed on surgical intervention, but advances in imaging techniques have helped identify features that may suggest a diagnosis of ISM. The various imaging patterns reported in children has been summarised in Table 2. Such imaging may provide valuable clues to diagnosis, clinical response and progression. Plain roentgenograms are usually non specific. However small-bowel series often show separation of loops with kinking and angulation of the small bowel, suggesting a serosal process. Folds may be thickened because of either extension of the mesenteric process into the submucosa or edema from lymphatic obstruction. The colon may occasionally be involved, with narrowing and rigidity; thumb printing also has been reported $[27,28]$. Ultrasonography may help delineate normal from inflammatory mesenteric fat, the latter demonstrating a homogenous echogenicity [29]. It has been reported in only 3 of the pediatric cases revealing a homogeneous low echoic mass in the involved areas. The CT appearance of sclerosing mesenteritis may vary from subtle increased attenuation in the mesentery to a solid soft- tissue mass. There may be preservation of fat around the mesenteric vessels, a phenomenon that is referred to as the "fat ring sign", a finding that may help distinguish sclerosing mesenteritis from other mesenteric processes such as lymphomas [30]. In addition, Sabate et al described the presence of a tumoral pseudocapsule in $50 \%$ of patients with mesenteric panniculitis [31]. Our case showed features of severe diffuse mesenteric adenopathy on CT. MRI usually reveals a low signal suggesting a mature fibrotic reaction. T2-weighted or fatsuppressed pulse sequences may help distinguish benign end stage fibrofatty proliferation from malignant tumours such as lymphoma [32]. Assessment of large to medium-sized vessels depicting the flow patterns and the presence of collaterals is also possible with MR imaging. MRI findings are reported in only 2 children with evidence of low signal intensities suggesting fibrosis in one case [21]. In our case, a young child, movement artefact degraded images on MR making interpretation difficult.

Most histopathological analyses show varied degree of fibrosis, chronic inflammation, and fat necrosis with the infiltrate being predominantly lymphocytes and eosinophils with no evidence of vasculitis or vascular thickening. Foci of dystrophic calcification have been occasionally reported [5]. The findings at biopsy in the pediatric series were consistent with macroscopic changes ranging from increased adipose tissue to widespread panniculitis and extensive fibrosis (Table 3).

No specific guidelines regarding the management of ISM exist and various medical and surgical modalities that have been tried. Use of anti-inflammatory, anti fibrotic and immunomodulatory agents such as corticosteroids, methotrexate, azathioprine, colchicine, thalidomide and Tamoxifen have all been reported either alone or in combination with varied degrees of success [6,7]. Thalidomide might act by modulating the production of tumor necrosis factor-alpha (TNF- $\alpha$ ) and other cytokines along with its inhibitory effects on angiogenesis [33]. Though reported in adults [34], our case is to our knowledge the first child to be treated with methotrexate. We used methotrexate because of the evidence of ongoing chronic inflammation and in part the reported role of methotrexate in ameliorating adiponectin which may thus inhibit the migration of macrophages to the mesenteric adipose tissue and suppress local TNF- $\alpha$ driven proinflammatory pathways [35].

Surgical exploration for diagnostic and therapeutic (adhesiolysis, debulking with or without resection anastomosis) purposes has been reported with all the children having some form of surgical intervention with only two cases not having actual tissue resection. Resection or debulking probably has a role in alleviating symptoms but may not help in prevention of disease progression. 
Table 2 Imaging modalities in idiopathic sclerosing mesenteritis in children

\begin{tabular}{lll}
\hline Pt no & Barium studies & CT \\
\hline 1 & Displaced DC, Small bowel obstruction, splenomegaly & NR \\
\hline 3 & $\begin{array}{l}\text { Initial normal, then thickened folds, segmentation of contrast } \\
\text { material. }\end{array}$ & NR \\
\hline 4 & Normal & NR \\
\hline 5 & Mass displacing cecum \&AC. & NR \\
\hline 6 & Mass \& narrowing AC. & NR \\
\hline 7 & NR & NR \\
\hline 8 & NR & Heterogeneous, solid TM between spleen, left kidney and pancreas \\
\hline 9 & Mass on medial AC & NR \\
\hline 10 & Normal & NR \\
\hline 11 & Narrowing of SC & NR \\
\hline 12 & NR & Soft Tm in mid abdomen around AC to DC. Retraction of TC, Dilated \\
\hline 13 & NR & AC \\
\hline 14 & NR & NR \\
\hline 15 & NR & NR \\
\hline 16 & Tumor mass displacing the Splenic flexure & Solid soft TM over the lower TC \\
\hline 17 & NR & E/O TM over the hepatic flexure \\
\hline
\end{tabular}

DC; Descending colon, NR; Not reported, AC; Ascending colon, TM; Tissue mass SC; sigmoid colon, TC; Transverse colon.

Table 3 Anatomic Involvement and pathological findings on biopsy.

\begin{tabular}{lll}
\hline Pt. no & Anatomic area of involvement & Pathology \\
\hline 1 & Mesentery (AC and TC) & FB with LI \\
\hline 3 & Mesentery (SB, largely at root) & Fat necrosis(early phase ) $\rightarrow$ Extensive FB (later ) \\
\hline 4 & Mesentery (TI), plaques on UT, OV, PP. & FB with absent residual fat \\
\hline 5 & T M in mesentery (TI, IC and Ap ) & FB with LI and PI. \\
\hline 6 & Mesentery (AC). & FB with LI and PI. \\
\hline 8 & TM (MG adherent to the Splenic artery) & FB with El. \\
\hline 9 & Mesentery (GC and TC ) & Panniculitis and severe fibrinoid necrosis. \\
\hline 10 & TM ( right colon and H (No obstruction )) & Severe inflammatory changes minimal FB. \\
\hline 11 & TM (Whole colon and MC (except RS) with perforation, normal SI. & FB \\
\hline 12 & Mesentery (IC) & FB with LI and foamy macrophages. \\
\hline 13 & TM & FB with necrosis and LI. \\
\hline 14 & Mesentery (TC ) & Increased adipose tissue with FB with necrosis and \\
\hline 15 & Greater omentum (TC) & LI. \\
\hline 16 & Mesentery (S) & FB with inflammatory infiltration. \\
\hline 17 & Extensive intraperitoneal adhesions, jejunal band with evidence of proximal & FB with inflammatory infiltration \\
\hline obstruction & FB with LI and PI. \\
\hline A As
\end{tabular}

AC; Ascending colon , TC; Transverse colon , FB; Fibrosis , LI; Lymphocytes infiltration , SB; Small bowel , I/TI; Ileum/Terminal Ileum, Ut; Uterus, Ov; Oviducts, TM; Tumour mass, PP; Parietal peritoneum, MG; Mesogastrium, BL; Broad ligaments, RS; Rectosigmoid colon, TM; Transverse mesocolon, S; Splenic flexure, IC; Ileocecum, GC; Gastrocolic omentum, H; Hepatic flexure El; Eosinophils infiltration, PL; Plasma cells, F; Fibroblasts 


\section{Conclusion}

Widely believed to have a good outcome in adults, the paucity of reported pediatric cases and long term follow up makes it difficult to plan management and prognosticate in children.

Decisions regarding the most appropriate form and duration of therapy in children should probably be guided by the severity and chronicity of symptomatology, growth of the child, and inflammatory markers. It seems rational that unless there is severe obstruction, medical/non-surgical management might be considered. Serial imaging is probably not indicated unless warranted by a clinical deterioration. Studies in adults have reported median duration of medical treatment between 2-30 months with recurrences up to 2 years after discontinuation though long term outcomes are not well reported [6]). Acute management of the condition with corticosteroids and introduction of a steroid sparing agent such as methotrexate if treatment seems likely be required for 3 months or more could be considered a reasonable. We suggest that treatment might be continued from at least 6 months from the time clinical and laboratory remission, as for other similar chronic inflammatory conditions of childhood.

Mortality secondary to ISM has been reported in 2 children and 4 adults $[16,18,33])$. Chronic inflammatory diseases have a much higher morbidity in growing children and a close follow up and individualisation of care is warranted with such a potentially variable course and outcome.

\section{Consent}

Written informed consent was obtained from the parents of the patient for publication of this case report and accompanying images. A copy of the written consent is available for review by the Editor-in-Chief of this journal.

\section{Acknowledgements}

The authors would like to acknowledge the efforts of Ms Ayako Nakayama, pediatric nurse for helping with linguistic interpretation of some of the literature.

\section{Authors' contributions \\ W was involved in the review of literature, analysis and drafting the manuscript. KJM was involved in management of the case and conceptualising the design and drafting of manuscript and will act as a guarantor. Both authors read and approved the final manuscript.}

\section{Competing interests}

The authors declare that they have no competing interests.

Received: 25 June 2009

Accepted: 21 January 2010 Published: 21 January 2010

\section{References}

1. Sulla JV: Mesenterite e sclerosante. Policlinico (sezprat) 1924, 31:575-81.

2. Durst AL, Freund H, Rossenmann E, Birnbaum D: Mesenteric panniculitis: Review of literature and presentation of cases. Surgery 1977, 81:203.
3. Vettoretto N, Doenico-Roberto D, Poiatti R, Matteucci R, Chioda C Giovanetti M: Occasional finding of mesenteric lipodystrophy during laparoscopy: a difficult diagnosis. World J Gastroenterol 2007, 28:5394-6.

4. White B, Kong A, Chang AL: Sclerosing mesenteritis. Australasian Radiology 2005, 49:185-88

5. Emory TS, Monihan JM, Carr NJ: Sclerosing mesenteritis mesenteric panniculitis and mesenteric lipodystrophy: a single entity?. Am J Surg Pathol 1997, 21:392-98.

6. Akram S, Pardi DS, Schaffner JA, Smyrk TC: Sclerosing mesenteritis: Clinical features treatment and outcome in ninety two patients. Clinical Gastroenterology and Hepatology 2007, 5:589-96.

7. Bala A, Coderre SP, Johnson DR, Nayak V: Treatment of sclerosing mesenteritis with corticosteroids and azathioprine. Can J Gastroenterol 2001, 15:533-35

8. Kipfer Re, Moertel CG, Dahlin DC: Mesenteric lipodystrophy. Ann Intern Medicine 1974, 80:582-588.

9. Parra-Davila E, McKenney MG, Sleeman D, Hartmann R, Rao RK, McKenney K, Compton RP: Mesenteric panniculitis: case report and literature review. Am Surg 1998, 64:768-771.

10. Schaffler A, Scholmerich J, Buchler C: Mechanisms of disease: adipocytokines and visceral adipose tissue-emerging role in intestinal and mesenteric diseases. Nat Clin Pract Gastroenterol Hepatol 2005, 2:103-111.

11. Hakguder G, Akgur FM, Olguner M, Ozer Erdener, Aktug T: A case of mesenteric panniculitis in a 4 year old child. Pediatrics International 2000, 42:577-78.

12. Schaffler A, Herfarth $\mathrm{H}$ : Creeping fat in Crohn's disease: travelling in a creeper lane of research?. Gut 2005, 54(6):742-744.

13. Phillips RH, Carr RA, Preston R, Pereira SP, Wilkinson ML, O'Donnell PJ, Thompson RP: Sclerosing mesenteritis involving the pancreas: two cases of a rare cause of abdominal mass mimicking malignancy. Eur J Gastrenterol Hepatol 1999, 11:1323-29.

14. Medina Franco H, Listinsky C, Wilcox CM, Morgan D, Heslin MJ: Concomitant sclerosing mesenteritis and bile duct fibrosis simulating Klatskins tumor. J Gastrointest Surg 2001, 5:658-660.

15. Chen TS, Montgomery EA: Are tumefactive lesions classified as sclerosing mesenteritis a subset of IgG4-related sclerosing disorders?. J Clin Pathol 2008, 61(10):1093-7.

16. Dor AM, Kohler JL, Aubrespy P, Scheiner CL, Pizzi M, Lebreuil G: Panniculite pseudotumorale Du meso astrosplenique. Sem Hop Paris 1982, 58:2847-50.

17. Soergel KH, Hensley G: Fatal mesenteric panniculitis. Gastrenterology 1966, 51:529.

18. Spark RB, Yakovac WC, Wagget J: Retractile sclerosing mesenteritis. Case report. Clin Pediatr (Phila) 1971, 10:119-22

19. McGee HJ, Taylor FA: Retractile (sclerosing) mesenteritis. Cancer Sem 1965, $3: 203$

20. Black W, Nelson D, Walker W: Multifocal subperitoneal sclerosis. Surgery $1968,63: 706-10$

21. Kawano S, Sanada $Y$, Yoshizawa $Y$, et al: Sclerosing Mesenteritis in children: A report of three cases. J Jpn Soc Pediatr Surg 2003, 39:59-64.

22. Melo CR, Melo IS, Christmann I: Sclerosing mesenteritis in a child. Report of a case. AMB Rev Assoc Med Bras 1980, 26:328-30.

23. Cakmak O, Tanyel FC, Caglar M, Gogus S: Mesenteric panniculitis mimicking acute abdomen in a 4-year-old child. Z Kinderchir 1986, 41:313-4.

24. Jona JZ, Glicklich M, Cohen RD: Sclerosing mesenteritis in a child. Arch Surg 1987, 122:735.

25. Davis CF, Guzzetta PC, Patterson K: Primary (retractile) mesenteritis in a child. J Pediatr Surg 1992, 27:1544-5.

26. Ueda D, Chiba S: Retractile mesenteritis in a 12-year-old girl: CT findings. Pediatr Radiol 1997, 27:342-4.

27. Han SY, Koehler RE, Keller FS, Ho KJ, Zomes SL: Retractile mesenteritis involving the colon: Pathologic and radiologic correlation. AJR 1986, 147:268-270.

28. Soler A, Sanchez J, Iglesias P, Samjurjo P, Ruiz J: Retractile mesenteritis involving the colon. AJR 1986, 147:937-940.

29. Roson N, Garriga V, Cuadrado M, Pruna X, Carbó S, Vizcaya S, Peralta A, Martinez M, Zarcero M, Medrano S: Sonographic findings of mesenteric panniculitis: correlation with $\mathrm{CT}$ and literature review. $S$ J Clin Ultrasound 2006, 34(4):169-76. 
30. Horton KM, Lawler LP, Fishman EK: CT findings in sclerosing mesenteritis (panniculitis): spectrum of disease. Radiographics 2003, 23:1561-7.

31. Sabate JM, Torrubia S, Maideu J, Franquet T, Monill JM, Perez C: Sclerosing mesenteritis: Imaging findings in 17 patients. Am J Roentgenol 1999, 172:625-629.

32. Kronthal AJ, Kang YS, Fishman EK, Jones B, Kuhlman JE, Tempany CM: MR imaging in sclerosing mesenteritis. Am J Roentgenol 1991, 156:517-9.

33. Ginsburg PM, Ehrenpreis ED: A pilot study of thalidomide for patients with symptomatic mesenteric panniculitis. Aliment Pharmacol Ther 2002, 16:2115-2122.

34. Katsanos KH, loachim E, Michail M, Price AC, Agnantis N, Kappas A, Tsianos EV: A fatal case of sclerosing mesenteritis. Dig Liver Dis 2004 36:153-6.

35. Serelis JK, Katsiougiannis S, Bletsa M, Tektonidou MG, Skopouli FN: Effect of anti-TNF treatment on body composition and serum adiponectin levels of women with rheumatoid arthritis. Clin Rheumatol 2008, 27:795-7.

doi:10.1186/1546-0096-8-5

Cite this article as: Viswanathan and Murray: Idiopathic sclerosing mesenteritis in paediatrics: Report of a successfully treated case and a review of literature. Pediatric Rheumatology 2010 8:5.

\section{Submit your next manuscript to BioMed Central} and take full advantage of:

- Convenient online submission

- Thorough peer review

- No space constraints or color figure charges

- Immediate publication on acceptance

- Inclusion in PubMed, CAS, Scopus and Google Scholar

- Research which is freely available for redistribution

Submit your manuscript at www.biomedcentral.com/submit 